\title{
Multiple sclerosis in South America: month of birth in different latitudes does not seem to interfere with the prevalence or progression of the disease
}

\author{
Esclerose múltipla na América do Sul: mês de nascimento em diferentes \\ latitudes não parece interferir com a prevalência ou progressão da doença
} Yára Dadalti Fragoso', Tarso Adoni², Sandra Maria Garcia de Almeida³, Soniza Vieira Alves-Leon³, Walter Oleschko Arruda4, Fiorella Barbagelata-Aguero 5 , Joseph Bruno Bidin Brooks ${ }^{1}$, Adriana Carra ${ }^{6}$, Rinaldo Claudino7, Elizabeth Regina Comini-Frota ${ }^{8}$, Eber Castro Correa ${ }^{9}$, Alfredo Damasceno ${ }^{10}$, Benito Pereira Damasceno ${ }^{10}$, Ethel Ciampi Díaz ${ }^{11}$, David George Elliff1, Ana Patrícia Peres Fiore ${ }^{12}$, Clelia Maria Ribeiro Franco ${ }^{13}$, Maria Cristina Brandao Giacomo ${ }^{14}$, Sidney Gomes ${ }^{15}$, Marcus Vinicius Magno Gonçalves ${ }^{16}$, Anderson Kuntz Grzesiuk17, Jose Luiz Inojosa ${ }^{13}$, Damacio Ramón Kaimen-Maciel'18, Katia Lin', Josiane Lopes ${ }^{18}$, Gisele Alexandre Lourenço $0^{4}$, Alejandra Diana Martínez ${ }^{6}$, Mario Oscar Melcon ${ }^{19}$, Nivea de Macedo Oliveira Morales ${ }^{20}$, Rogério Rizo Morales ${ }^{20}$, Marcos Moreira ${ }^{21}$, Shirlene Vianna Moreira ${ }^{21}$, Celso Luis da Silva Oliveira1, Francisco Tomaz Menezes de Oliveira ${ }^{15}$, João Batista Ribeiro ${ }^{22}$, Sonia Beatriz Felix Ribeiro22, Claudia Cárcamo Rodriguez ${ }^{11}$, Liliana Russo ${ }^{14}$, Juliana Safanelli16, Kirsty Deborah Shearer ${ }^{24}$, Fabio Siquineli23, Darwin Vizcarra-Escobar ${ }^{5}$

\footnotetext{
'Department of Neurology, Universidade Metropolitana de Santos, Santos SP, Brazil;

2Department of Neurology, Hospital Sirio Libanes, São Paulo SP, Brazil;

${ }^{3}$ Department of Neurology, Universidade Federal do Rio de Janeiro, Rio de Janeiro RJ, Brazil;

${ }_{4}^{4}$ Department of Neurology, Universidade Federal do Parana, Curitiba PR, Brazil;

${ }^{5}$ HYPNOS, Clinica San Felipe, Lima, Peru;

${ }^{6}$ Department of Neurology, Hospital Britanico de Buenos Aires, Buenos Aires, Argentina;

${ }^{7}$ Department of Neurology, Universidade Federal de Santa Catarina, Florianopolis PR, Brazil;

${ }^{8}$ Department of Neurology, Universidade Federal de Minas Gerais, Belo Horizonte MG, Brazil;

${ }^{9} \mathrm{CLINEN}$, Neurology and Endocrinology, Brasilia DF, Brazil;

${ }^{10}$ Department of Neurology, Universidade Estadual de Campinas, Campinas SP, Brazil;

11Department of Neurology, Pontificia Universidad Católica de Chile, Santiago, Chile;

${ }^{12}$ Cruzada Bandeirante São Camilo Assistencia Medico Social, Santos SP, Brazil;

${ }^{13}$ Department of Neurology, Hospital de Clinicas, Universidade Federal de Pernambuco, Recife PE, Brazil;

${ }^{14}$ Neurology Clinic, São Paulo SP, Brazil;

${ }^{15}$ Hospital Beneficencia Portuguesa and Hospital Paulistano, São Paulo SP, Brazil;

${ }^{16}$ Department of Neurology, Universidade da Regiao de Joinville, Joinville SC, Brazil;

${ }^{17}$ Centro de Reabilitação Integral Dom Aquino Correa, Cuiaba MT, Brazil;

${ }^{18}$ Department of Neurology, Universidade Estadual de Londrina, Londrina PR, Brazil;

${ }^{19}$ Fundación para la Investigacion en Neuroepidemiología, Buenos Aires, Argentina;

${ }^{20}$ Department of Neurology, Universidade Federal de Uberlandia, Uberlândia MG, Brazil;

${ }^{21}$ Clinical Neuroimmunology Unit, Hospital Therezinha de Jesus, FCMS Suprema, Juiz de Fora MG, Brazil;

${ }^{22}$ Department of Neurology, Universidade Federal do Triangulo Mineiro, Uberaba MG, Brazil;

${ }^{23}$ Institute of Medical Sciences, University of Aberdeen, Scotland, UK;

${ }^{24}$ Department of Neurology, Hospital Santa Isabel, Universidade Regional de Blumenau, Blumenau SC, Brazil.

Correspondence: Yara Dadalti Fragoso; Departamento de Neurologia, Escola de Medicina UNIMES; Rua da Constituição 374; $11015-470$ Santos SP - Brasil; E-mail:yara@bsnet.com.br

Conflict of interest: There is no conflict of interest to declare.

This study was awarded a prize for "best poster" in the Latin American Congress of Treatment and Research in Multiple Sclerosis (LACTRIMS) 2012.

Received 5 December 2012; Received in final form 12 April 2013; Accepted 19 April 2013.
} 


\section{ABSTRACT}

Objective: To assess whether the month of birth in different latitudes of South America might influence the presence or severity of multiple sclerosis (MS) later in life. Methods: Neurologists in four South American countries working at MS units collected data on their patients' month of birth, gender, age, and disease progression. Results: Analysis of data from 1207 MS patients and 1207 control subjects did not show any significant variation in the month of birth regarding the prevalence of MS in four latitude bands (0-10; 11-20; 21-30; and 31-40 degrees). There was no relationship between the month of birth and the severity of disease in each latitude band. Conclusion: The results from this study show that MS patients born to mothers who were pregnant at different Southern latitudes do not follow the seasonal pattern observed at high Northern latitudes.

Key words: South America, multiple sclerosis, sun exposure.

\section{RESUMO}

Objetivo: Avaliar se o mês de nascimento em diferentes latitudes da América do Sul pode influenciar a presença ou gravidade da esclerose múltipla (EM) na vida. Método: Neurologistas de quatro países da América do Sul trabalhando em unidades de EM coletaram os dados de seus pacientes com referência ao mês de nascimento, gênero, idade e progressão da doença. Resultados: A análise dos dados mostrou que, para 1207 pacientes com EM e 1207 controles, não havia diferença significativa no mês de nascimento com relação à prevalência de EM em quatro zonas de latitude (0-10;11-20; 21-30; e 31-40 graus). Não houve relação entre o mês de nascimento e a gravidade da doença em nenhuma destas zonas. Conclusão: Os resultados deste estudo mostram que pacientes com EM nascidos de mães grávidas em diferentes latitudes sul não seguem o padrão dos resultados sazonais encontrados nas latitudes norte.

Palavras-Chave: América do Sul, esclerose múltipla, exposição solar.

It has been suggested that the month in which a person is born and the development of multiple sclerosis (MS) might be related through the influence of the mother's exposure to sunlight during pregnancy, thus possibly affecting vitamin D metabolism. This theory has been supported by data from several countries in the Northern hemisphere, such as Denmark ${ }^{1}$, Hungary $^{2}$, Italy ${ }^{3}$, Sweden ${ }^{4}$, Scotland ${ }^{5}$. Finland, ${ }^{6}$ and France ${ }^{7}$. A pooled database from Canada, the UK, Sweden, and Denmark $^{8}$ that included nearly 40,000 patients also confirmed these findings. All of these studies showed that greater numbers of individuals with MS were born at the end of the winter season in countries with high latitudes. A recent study from the USA ${ }^{9}$ did not confirm a clear trend of seasonality for the incidence of MS. The Australian study ${ }^{10}$, performed with individuals in latitudes $30^{\circ}$ to $46^{\circ}$ South showed a tendency to higher prevalence of MS in the offspring depending only on the first trimester of pregnancy. This finding is different from that of the Northern hemisphere, where the third trimester was apparently the time where sun exposure of the mother-to-be was important. Two studies on the same subject carried out at latitudes of approximately $30^{\circ}$ North (Israel ${ }^{11}$ ) and $29^{\circ}$ South (Brazil ${ }^{12}$ ) demonstrated that the month of birth did not influence subsequent development of MS in these geographically subtropical regions, where daylight exposure does not vary so much between different seasons. To date, no study has included a wide range of latitudes, comparing the prevalence of MS according to the month of birth between regions on the same continent. Furthermore, disease progression was not shown to be influenced by the month of birth in the Netherlands ${ }^{13}$, while a small but long-lasting influence was observed in Canada ${ }^{14}$. The effects of seasonality on MS progression in South America are, as yet, unknown.

The present study aimed to assess whether the month of birth might influence the development and severity of MS across a wider geographical region of South America. In addition, disease progression according to the month of birth was also assessed.

\section{METHODS}

This study was approved by the institutions participating in data collection. Data were gathered from four South American countries (Argentina, Brazil, Chile, and Peru) over a three-month period. A specific file containing all pertinent details of the patient's medical history was filled out by the neurologist in charge of that particular case. All patients were under the care of the physician who forwarded the data, and their diagnoses of MS were confirmed in accordance with the criteria established at the time of this diagnosis ${ }^{15-17}$. The data file consisted of age, gender, city of birth, date of birth, disease duration, and present disability as assessed by the expanded disability status scale (EDSS) ${ }^{18}$. Patients' confidentiality was maintained and no identification by name or initials was included in the database. In order to avoid duplicate cases, patients born at the same city were checked for date of birth and gender. Whenever necessary, the physicians in charge were contacted to clarify whether the patient might be the same one, receiving care from two different physicians.

A control group was also included in the study for direct comparison of month of birth, comprising males and females born at the same latitude levels and of similar ages to the patients with MS. These controls were not relatives of the patients and had similar backgrounds regarding ethnicity and socioeconomic levels. Some of the control individuals were obtained from the hospital records of non-neurological patients who did not have immune-related diseases. Other control subjects were 
also recruited among hospital employees and individuals (nonrelatives) accompanying patients for medical or dental consultations. The MS patients and control subjects were grouped according to the latitude at which they had been born into four bands: $0^{\circ}$ to $10^{\circ}$ South; $11^{\circ}$ to $20^{\circ}$ South; $21^{\circ}$ to $30^{\circ}$ South; and $31^{\circ}$ to $40^{\circ}$ South. The month of birth of each individual (patients and controls) and the patients' clinical disability reached over a certain period of time (disease duration) were registered and analyzed separately in each of these four bands.

GraphPad Prism was used for statistical evaluation. Twoway and one-way ANOVA, chi-square analysis, linear regression analyses, Pearson's correlation, and Student's $t$-test were used to analyze the results. Significant values were those with $\mathrm{p}<0.05$.

\section{RESULTS}

The total population samples comprised 1207 MS patients and 1207 control subjects. The patients with MS and the controls were of similar age, that is, $40.8 \pm 12.6$ years old for patients and $40.6 \pm 15.5$ for controls. Males and females were also similarly distributed between the patient and control groups, that is, 351 males and 856 females with MS and 396 males and 811 females as controls. A summary of the demographic data for the MS patients and controls is summarized in Table. All groups were comparable, except for the patients living at latitudes $0^{\circ}$ to $10^{\circ}$ South. These patients were significantly older than the other groups $(p=0.008)$, had significantly longer disease duration $(\mathrm{p}=0.04)$, and had significantly higher EDSS ( $p=0.001)$ than the other patients.

The distribution of months and seasons of births of all MS patients and controls is shown in Fig 1A. There were no significant differences in the two groups when all the latitude bands $\left(0^{\circ}\right.$ to $\left.40^{\circ}\right)$ were considered. Two-way ANOVA analysis on the data did not show any significant variation in MS prevalence in relation to month of birth, in any of the four Southern latitude bands evaluated, as shown in Fig 1B. The data were further analyzed according to the season of birth and, again, there were no significant differences between the patients with MS and the controls (Fig 1C). These results were confirmed with chi-square univariate analysis of the samples $(\mathrm{p}=0.8255)$.

As would be expected, a direct correlation existed between EDSS score and length of the disease for the whole group of patients with MS, irrespective of the latitude $(p<0.0001)$, as assessed using Pearson's correlation test $(r=0.479)$. This result is summarized in Fig 2A. This correlation between EDSS score and length of the disease was also observed in each of the latitude bands separately as shown in Fig 2A, that is, the longer the disease duration, the higher the EDSS (Figs 2C and D). Using Pearson's correlation, the EDSS/disease duration was significantly correlated at latitudes $0^{\circ}$ to $10^{\circ}(\mathrm{p}<0.007$ and $\mathrm{r}=0.4518)$; latitudes $11^{\circ}$ to $20^{\circ}$ $(\mathrm{p}<0.0001$ and $\mathrm{r}=0.4463)$; latitudes $21^{\circ}$ to $30^{\circ}(\mathrm{p}<0.0001$ and $\mathrm{r}=0.4845)$; and latitudes $31^{\circ}$ to $40^{\circ}(\mathrm{p}<0.0001$ and $\mathrm{r}=0.4830)$. There was no difference in disease progression in relation to the month or season of birth (Figs 3A-D).

\section{DISCUSSION}

The results from this study show that children born from pregnancies at higher latitudes in South America do not show higher incidence of MS later in life, as is the case with the seasonal pattern observed in the Northern hemisphere ${ }^{1-9}$. Therefore, it cannot be affirmed that there is a clear relationship between lower sun exposure in winter pregnancies and the development of MS later in the offspring's life in South America. Even if it is argued that the sample of this study is much smaller due to the lower prevalence of MS in South America in relation to Northern hemisphere countries, the Australian study carried out in $2010^{10}$ also used a similar number of patients to come to their conclusions. Other factors such as mixed ethnicity in South America should not

Table. Demographic and clinical data of patients with multiple sclerosis and control subjects.

\begin{tabular}{|c|c|c|c|c|c|c|c|c|}
\hline \multirow{2}{*}{ Latitudes } & \multicolumn{5}{|c|}{ MS patients } & \multicolumn{3}{|c|}{ Control subjects } \\
\hline & $\begin{array}{l}\text { Number of } \\
\text { subjects }\end{array}$ & Age (years) & $\begin{array}{l}\text { Disease } \\
\text { duration }\end{array}$ & Gender & EDSS & $\begin{array}{l}\text { Number of } \\
\text { subjects }\end{array}$ & Age (years) & Gender \\
\hline $0^{\circ}$ to $10^{\circ}$ & 34 & $46.1 \pm 13.7^{*}$ & $10.2 \pm 7.1^{\star}$ & $\begin{array}{l}M=13 \\
F=21\end{array}$ & $4.17 \pm 2.46^{*}$ & 34 & $41.9 \pm 12.3$ & $\begin{array}{l}M=13 \\
F=21\end{array}$ \\
\hline $11^{\circ}$ to $20^{\circ}$ & 196 & $38.1 \pm 13.0$ & $8.5 \pm 6.7$ & $\begin{array}{l}M=53 \\
F=143\end{array}$ & $2.72 \pm 2.39$ & 196 & $38.3 \pm 12.2$ & $\begin{array}{l}M=70 \\
F=126\end{array}$ \\
\hline $21^{\circ}$ to $30^{\circ}$ & 700 & $40.3 \pm 12.3$ & $7.9 \pm 6.4$ & $\begin{array}{c}M=190 \\
F=510\end{array}$ & $2.47 \pm 2.26$ & 700 & $39.6 \pm 13.9$ & $\begin{array}{l}M=220 \\
F=480\end{array}$ \\
\hline $31^{\circ}$ to $40^{\circ}$ & 277 & $41.3 \pm 12.9$ & $8.5 \pm 7.2$ & $\begin{array}{l}M=95 \\
F=182\end{array}$ & $2.07 \pm 2.40$ & 277 & $43.2 \pm 18.9$ & $\begin{array}{l}M=93 \\
F=184\end{array}$ \\
\hline Total & 1207 & $40.8 \pm 12.6$ & $8.2 \pm 5.7$ & $\begin{array}{l}M=351 \\
F=856\end{array}$ & $2.48 \pm 2.34$ & 1207 & $40.2 \pm 15.4$ & $\begin{array}{l}M=396 \\
F=811\end{array}$ \\
\hline
\end{tabular}

*Patients living at latitudes $0-10^{\circ}$ South were significantly older than the other groups ( $p=0.08$ ), had significantly higher disease duration ( $p=0.04$ ), and had significantly higher expanded disability scale score (EDSS) $(p=0.001)$ than other patients. Age, disease duration, and expanded disability scale score ${ }^{18}$ are expressed as mean value \pm standard deviation. 
interfere in the month of birth, even if it can interfere in some manner in the development of MS.

Findings from the present study are likely to be explained by geographical reasons. In making comparisons between the Northern and Southern hemispheres, it has to be borne in mind that latitudes considered to be substantially southerly in South America are low in Northern hemisphere terms. The southern limit of the present study ( $40^{\circ}$ South) was at the northern limit of Patagonia, a vast sparsely populated area of relatively severe climate. However, the same latitude in the Northern hemisphere ( $40^{\circ}$ North) is far from being considered very northerly: it passes just north of San Francisco and Washington DC, and just south of Madrid and Rome. There is no land mass in South America equivalent to the high northerly latitudes of Europe. For example, Finland is at latitudes equivalent to the Antarctic Peninsula.

Sun exposure may be an important factor in relation to month of birth and MS at very high northern latitudes.
However, it can clearly be seen that the amount of sun exposure at $40^{\circ}$ South will be substantially greater than at northern latitudes further from the Equator than the southern tip of South America (e.g., Scotland or Sweden).

It is interesting to observe that seasonality may have an influence on MS relapses, as recently described in a Brazilian city at tropical latitude ${ }^{19}$. The influence of sunlight, climate, and geographical characteristics of a city are indeed interesting aspects of the environment, with regard to MS development and profile, and this may differ depending on the city or country studied. However, several other factors, including genetic profile and infections, may play a more important role in MS development and severity in the countries assessed here. For example, it is possible that the age at which children start to play outdoors might influence the infections that this child acquires in early childhood. Early contact with helminths may alter the immunological system and influence the development of
A

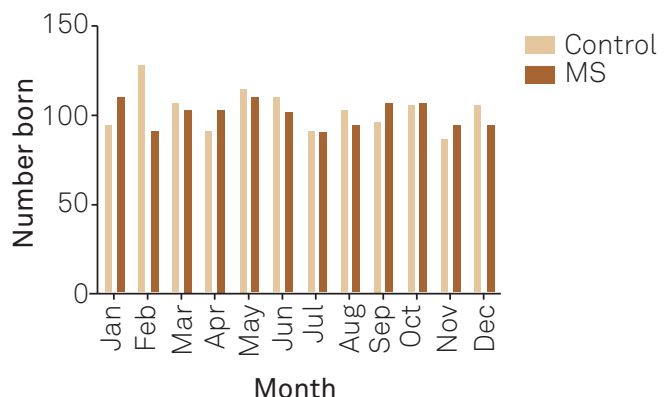

B
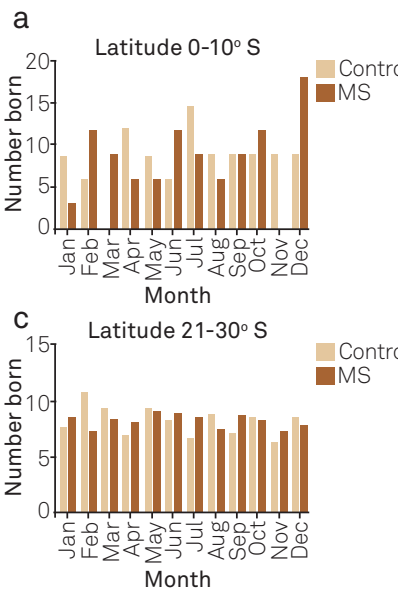

b

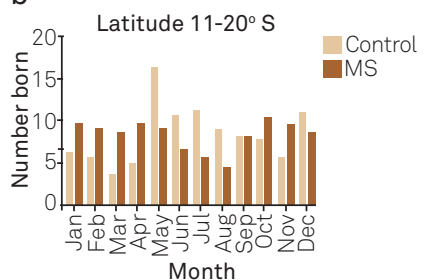

d
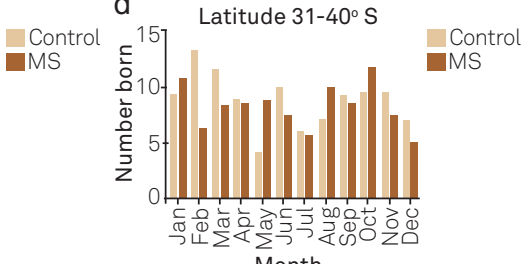
Contro
MS d Latitude $31-40^{\circ} \mathrm{S}$

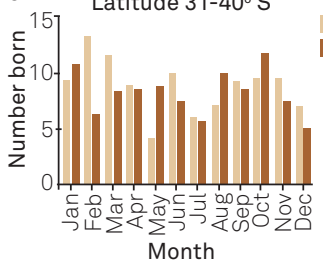

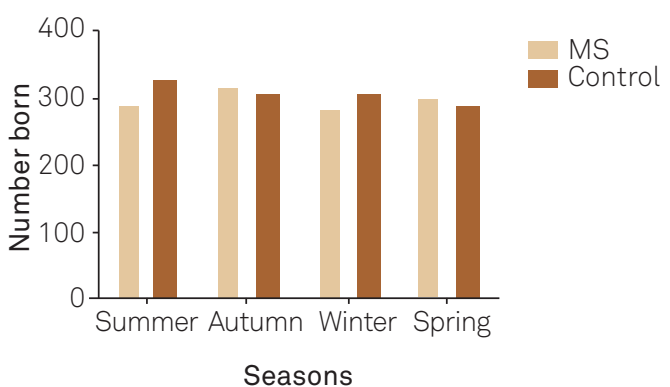

C

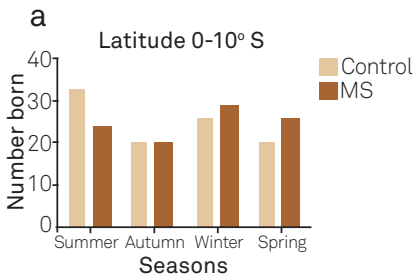

b season birth $11-20$
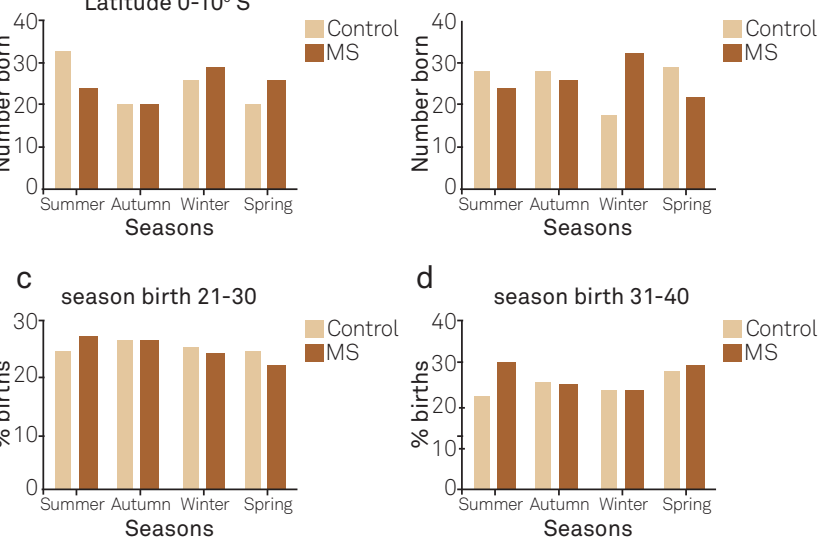

d

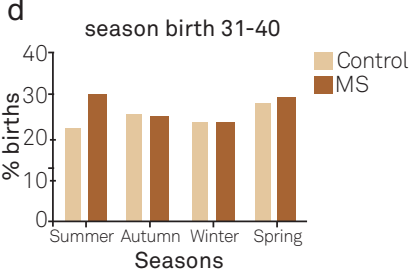

Fig 1. (A) Month and season of birth of patients with multiple sclerosis and control subjects, irrespective of the latitude they were born in South America. There are no significant differences between patients and controls. (B) Month of birth of patients with multiple sclerosis and control subjects, grouped into four different latitude bands, showing that there were no significant differences between patients with MS and controls. Data were analyzed using two-way ANOVA and expressed as percentage numbers of births for MS patients and control subjects for each month, considering the different latitude bands: $0-10^{\circ} \mathrm{S}$ $(p=0.7) ; 11-20^{\circ} \mathrm{S}(p=0.8) ; 21-30^{\circ} \mathrm{S}(\mathrm{p}=0.6)$; and $31-40^{\circ} \mathrm{S}(\mathrm{p}=0.5)$. (C) Season of birth of patients with multiple sclerosis and controls subjects, grouped into four different latitude bands $\left(0-10^{\circ} ; 11-20^{\circ} ; 21-30^{\circ} ; 31-40^{\circ}\right)$, showing that there were no significant differences between patients with MS and controls. Data were analyzed using two-way ANOVA. The seasons in the South American countries participating in this study were defined as follows: March to May = autumn; June to August = winter; September to November = spring; December to February = summer. 
autoimmune diseases ${ }^{20}$. Since exposure to helminths and other parasites may have a protective effect with regard to later development of $\mathrm{MS}^{21}$, the mother's exposure to sunlight during pregnancy may only be one component of the complex environmental factors associated with MS in South America. For example, it has been argued that the mother's food intake and nutritional status may affect the child's outcome in future life, including the likelihood of developing $\mathrm{MS}^{22}$.

Gradients of MS prevalence have been observed in New Zealand $^{23}$ and Central and South America ${ }^{24}$. However, at least in South America, the month of birth cannot be considered to be as significant for MS prevalence as it seems to be in Northern hemisphere populations. This finding is not surprising when all the geographical considerations above mentioned are considered.

A very recent study from Dobson, Giovannoni and Ramagopalan ${ }^{25}$ reviewed the subject of month of birth and prevalence of MS in a systematic manner. Unfortunately, the only two Southern hemisphere studies (Australian ${ }^{10}$ and Brazilian ${ }^{12}$ ) were considered to have (according to the authors) "data that could not be used for meta-analysis" despite the high impact factor journals they had been published. As one of the studies was performed by our group, we can also say that those authors ${ }^{25}$ did not try to contact our group for more information or data. They concluded that in the Northern hemisphere there is a clear relationship between the month of birth and the subsequent risk of $\mathrm{MS}^{25}$. However, in the Southern hemisphere, the Australians have a completely different finding in relation to the time of pregnancy when the sun exposure might be relevant, while the previous Brazilian and now the South American study systematically show that the month of birth does not seem to influence the risk of MS.

Finally, and very importantly, it is essential to highlight the fact that epidemiological studies of MS in South America will never have the number of patients found in North America. Over 40 researchers from four countries added their data in order to obtain the results presented here. In some areas of South America, the prevalence of MS is as low as $1.5 / 100,000^{24}$, and many areas of the continent do not even have prevalence studies. For well-powered confirmation of the null hypothesis in the present study, tens of thousands of patients would be necessary. Other particular aspects of South American populations, such as ethnicity, were accounted for with the control groups obtained in each region of the present work. Despite these inherent limitations, the present study seems to confirm the idea that maternal exposure to sunlight may have an influence on the development of MS later in the life of an individual where sunlight exposure is indeed limited by severe winters.

In conclusion, the month or season of birth of the patients with MS in South America was not significantly different from the general population. Likewise, disease progression did not correlate with the month or season of birth of these South American patients with MS. The information from the North America and Europe once again may not be applicable to our continent, and it is imperative that our results are known rather than ignored in favor of North American and European data.
A

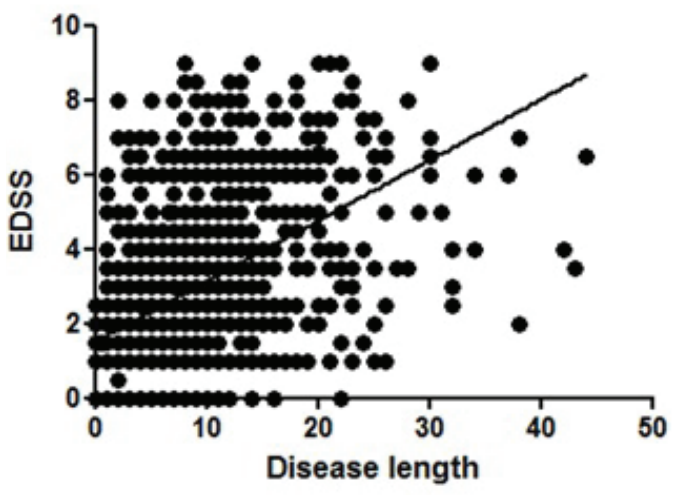

B

A
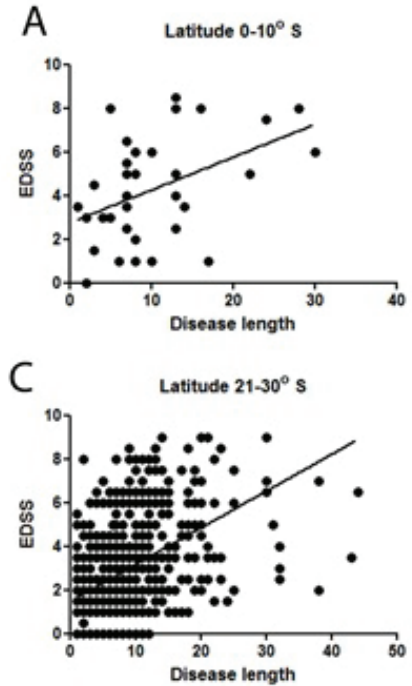

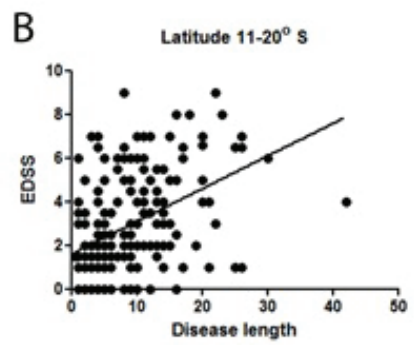

D

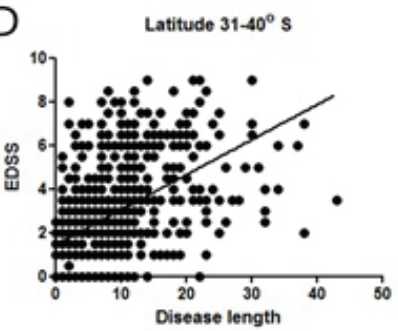

Fig 2. (A) Correlation of accumulated disability (expanded disability scale score /disease duration in years) for all multiple sclerosis patients, irrespective of the latitude at which they were born $\left(r^{2}=0.2298\right)$, assessed using Pearson's correlation, showing that the longer the disease duration, the greater the disability ( $<<0.0001)$. (B) Correlation of accumulated disability (expanded disability scale score/disease duration in years) for all multiple sclerosis patients according to southern latitude categories: $0-10^{\circ}$ $(p<0.007) ; 11-20^{\circ}(p<0.0001) ; 21-30^{\circ}$ ( $\left.p<0.0001\right)$; and latitudes 31-40 $(p<0.0001)$. Assessment using Pearson's correlation. 


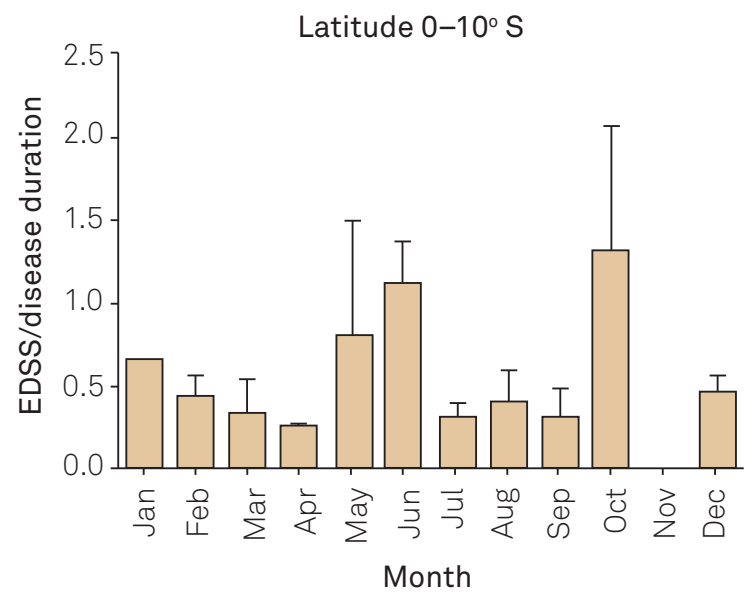

C

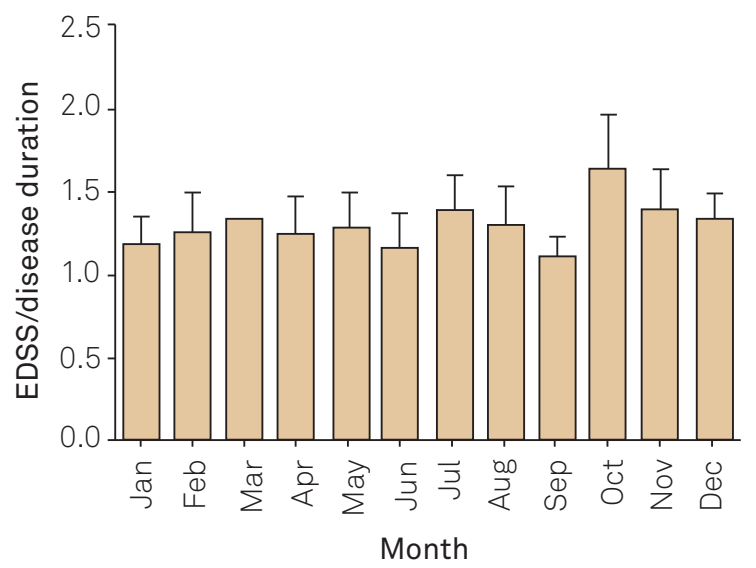

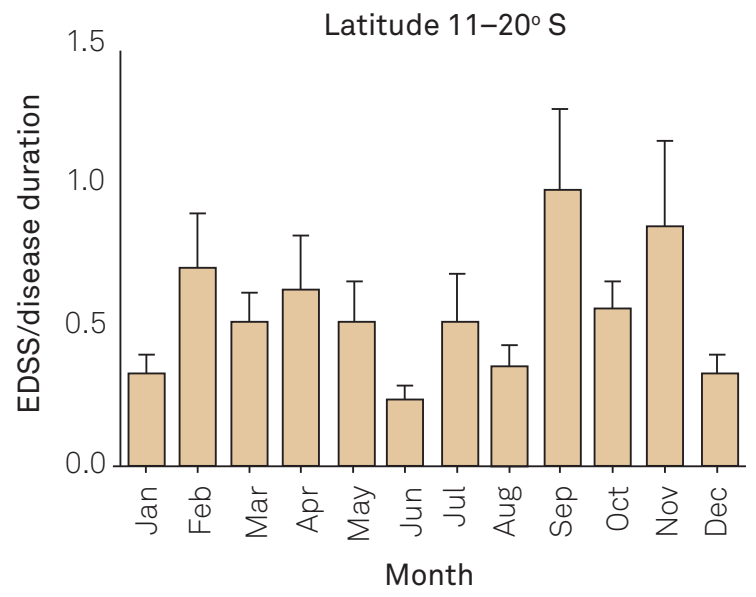

D

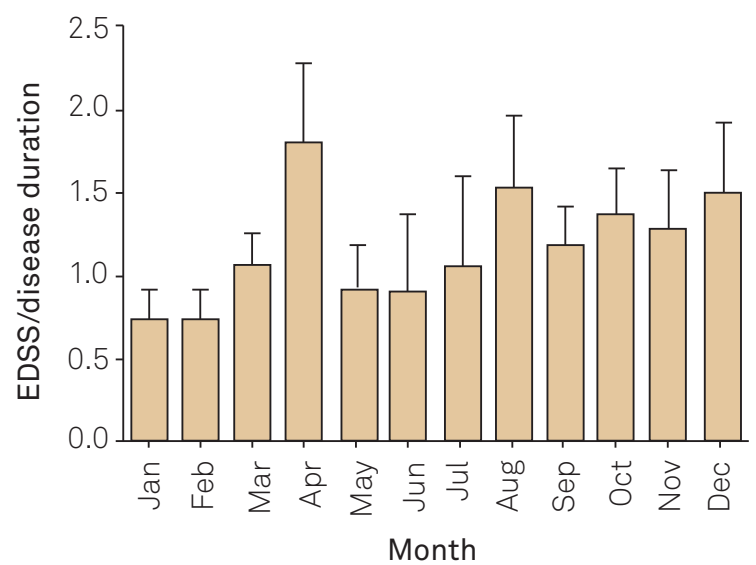

Fig 3. Disability progression in multiple sclerosis patients as determined by disease length/ expanded disability scale score for each month of birth in the different southern latitude bands $0-10^{\circ}(p=0.9), 11-20^{\circ}(p=0.6), 21-30^{\circ}(p=0.6)$, and $31-40^{\circ}(p=0.5)$. Assessment using one-way ANOVA.

\section{References}

1. Templer DI, Trent NH, Spencer DA, et al. Season of birth in multiple sclerosis. Acta Neurol Scand 1992;85:107-109.

2. Bharanidharan P. Monthly distribution of multiple sclerosis patients' births. Int J Biometeorol 1997;40:117-118.

3. Salemi G, Ragonese P, Aridon P, et al. Is season of birth associated with multiple sclerosis? Acta Neurol Scand 2000;101:381-383.

4. Salzer J, Svenningsson A, Sundström P. Season of birth and multiple sclerosis in Sweden. Acta Neurol Scand 2010;122:70-73.

5. Bayes HK, Weir CJ, O'Leary C. Timing of birth and risk of multiple sclerosis in the Scottish population. Eur Neur 2010;63:36-40.

6. Saastamoinen KP, Auvinen MK, Tienari PJ. Month of birth is associated with multiple sclerosis but not with HLA-DR15 in Finland. Mult Scler 2012;18:563-568.

7. Fernandes de Abreu DA, Babron MC, Rebeix I, et al. Season of birth and not vitamin D receptor promoter polymorphisms is a risk factor for multiple sclerosis. Mult Scler 2009;15:1146-1152.
8. Willer CJ, Dyment DA, Sadovnick AD, et al. Canadian Collaborative Study Group. Timing of birth and risk of multiple sclerosis: population based study. BMJ 2005;330:120.

9. Deussing EC, Jankosky CJ, Clark LL, et al. Estimated incidence of multiple sclerosis among United States Armed Forces personnel using the Defense Medical Surveillance System. Mil Med 2012;177:594-600.

10. Staples J, Ponsonby AL, Lim L. Low maternal exposure to ultraviolet radiation in pregnancy, month of birth, and risk of multiple sclerosis in offspring: longitudinal analysis. BMJ 2010;340:1640.

11. Givon U, Zeilig G, Dolev M, et al. The month of birth and the incidence of multiple sclerosis in the Israeli population. Neuroepidemiology 2012;38:64-68.

12. Fragoso YD, Shearer KD, Adoni T, et al. Month of birth does not seem to interfere with the development of multiple sclerosis later in life in Brazilian patients. Neuroepidemiology 2012;39:70-71.

13. Koch M, De Keyser J, Tremlett H. Timing of birth and disease progression in multiple sclerosis: Mult Scler 2008;14:793-798. 
14. TremlettHL, DevonshireVA.Does the season or month of birth influence disease progression in multiple sclerosis? Neuroepidemiology 2006;26:195-198.

15. Poser CM, Paty DW, Scheinberg L, et al. New diagnostic criteria for multiple sclerosis: guidelines for research protocols. Ann Neurol 1983;13:227-231.

16. McDonald WI, Compston A, Edan G, et al. Recommended diagnostic criteria for multiple sclerosis: guidelines from the International Panel on the diagnosis of multiple sclerosis. Ann Neurol 2001;50:121-127.

17. Polman $\mathrm{CH}$, Reingold SC, Edan G, et al. Diagnostic criteria for multiple sclerosis: 2005 revisions to the "McDonald Criteria". Ann Neurol 2005;58:840-846.

18. Kurtzke JF. Rating neurologic impairment in multiple sclerosis: an expanded disability status scale (EDSS). Neurology (Cleveland) 1983;33:1444-1452.

19. Damasceno A, Von Glehn F, de Deus-Silva L, et al. Monthly variation of multiple sclerosis activity in the Southern hemisphere: analysis from 996 relapses in Brazil. Eur J Neurol 2012;19:660-662.
20. Altmann DM. Review series on helminths, immune modulation and the hygiene hypothesis: nematode coevolution with adaptive immunity, regulatory networks and the growth of inflammatory diseases. Immunology 2009;126:1-2.

21. Correale J, Farez MF. The impact of environmental infections (parasites) on MS activity. Mult Scler 2011;17:1162-1169.

22. Watson PE, McDonald BW. Seasonal variation of nutrient intake in pregnancy: effects on infant measures and possible influence on diseases related to season of birth. Eur J Clin Nutr 2007;61:1271-1280.

23. Melcon M, Melcon C, Bartoloni L, et al.; the "Grupo Colaborativo Multicéntrico para el Estudio de la Esclerosis Multiple en America Latina y el Caribe" (GEEMAL). Towards establishing MS prevalence in Latin America and the Caribbean. Mult Scler 2013;19:145-152.

24. Taylor BV, Pearson JF, Clarke G, et al. MS prevalence in New Zealand, an ethnically and latitudinally diverse country. Mult Scler 2010;16: 1422-1431.

25. Dobson R, Giovannoni G, Ramagopalan S. The month of birth effect in multiple sclerosis: systematic review, meta-analysis and effect of latitude.J Neurol Neurosurg Psychiatry 2013;84:427-432. 